\title{
La inversión extranjera directa como palanca de crecimiento económico
}

\section{Direct foreign investment as a lever for economic growth}

Dussel Peters, Enrique (COORD.) (2007), INVERSIÓN EXTRANJeRA

DIRECTA EN MÉXICO: DESEMPEŃO Y POTENCIAL. UNA PERSPECTIVA MACRO,

MESO, MICRO Y TERRITORIAL, Siglo XXI-UNAM, MÉXico, 359 PP.,

ISBN: 978-968-23-27I 5-5 (SigLO XXI), 978-970-32-5072-I (UNAM).

El texto Inversión extranjera directa en México: desempeño y potencial. Una perspectiva macro, meso, micro y territorial es un libro escritor por Enrique Dussel, Luis Miguel Galindo, Eduardo Loría y Michael Mortimore, todos ellos con sólido prestigio académico, miembros del Sistema Nacional de Investigadores y profesores e investigadores en prestigiadas universidades y centros de investigación.

El texto de referencias representa un valioso esfuerzo de análisis y reflexión acerca de la inversión extranjera directa (IED), además, es lectura obligada para todos aquellos interesados en el tema, dado su enfoque profundo, contemporáneo, local e internacional.

En la contraportada se señala: "Con más de 77,000 empresas trasnacionales y 62 millones de empleos, la IED juega un papel formidable en las actuales economías a nivel global y en América Latina. [...] Sin lugar a dudas puede convertirse en un importante motor de crecimiento de las economías locales y nacionales. El documento busca [...] hacer un aporte efectivo en cuanto a las condiciones y el potencial de la IED en México".

El texto se divide en siete capítulos: en el primero se ofrece un panorama internacional de la IED; el segundo señala los determinantes macroeconómicos de la IED en México durante el periodo 1970-2005; el tercer capítulo presenta la normatividad de la IED por sectores, origen y destino; el cuarto capítulo analiza la IED en el ámbito de clases económicas y por entidad federativa; el quinto presenta la IED de Japón en México; el capítulo sexto muestra la importancia de la IED en Jalisco; finalmente, el capítulo séptimo ofrece las conclusiones y propuestas de política. Es importante señalar que cada uno de los apartados incluye conclusiones preliminares e interesantes propuestas de política. 


\section{Panorama internacional de la IED}

En este momento de crisis financiera mundial, en el cual se cuestiona fuertemente al sector financiero, se hace necesario considerar a la inversión extranjera directa como un elemento alternativo para salir de la crisis. Como señalan los autores: "La inversión extranjera directa puede hacer una contribución muy importante al crecimiento y desarrollo de los países. Tal hecho ha sido evidente en países industriales" (p. 11).

En medio de una crisis financiera mundial es importante preguntarnos: ¿quién o quiénes deben invertir para que sea la IED el motor para salir de la crisis? Las empresas, imposible, porque no ven perspectivas de ganancia, por ello, consideramos que debe ser el Estado. Un Estado benefactor como lo concibió Keynes en la década de los veinte del siglo pasado. Mientras el Estado no participe, se debe esperar, por tanto, una reactivación económica a partir de la IED, no sólo extranjera, sino también nacional.

El objetivo del primer capítulo es analizar la información estadística mundial de la IED y las operaciones de las Compañías Transnacionales (CTN).

Después de repasar las estadísticas de la IED mundial, los autores llegan a las siguientes conclusiones. Actualmente, los países subdesarrollados ya no buscan atraer cualquier tipo de IED; les preocupa atraer aquélla que genera beneficios para la economía receptora.

\footnotetext{
Como se mencionó anteriormente, el enfoque de las evaluaciones sobre los beneficios para el desarrollo de entrada de la IED se ha trasladado de la premisa dominante original que aseguraba que la IED es, por su propia naturaleza, un elemento que favorece al desarrollo, al punto de vista más defendible que sugiere que la IED puede tener efectos tanto positivos como negativos, y por lo tanto se justifica la intervención política en aras de maximizar su beneficio y minimizar sus costos (p. 27).
}

Después de revisar los efectos de la IED por regiones, se concluye que los países latinoamericanos y del Caribe muestran experiencias frustradas que contrastan con otras naciones, las cuales han tenido éxito al utilizar la IED positivamente. Dichas naciones, mediante estrategias de desarrollo nacional, generaron lo que los autores denominan escalar (catch up) hacia las economías industriales, esto es, lograr un cambio estructural que les permitiera ser más competitivas en actividades industriales más complejas tecnológicamente. Por su parte, las empresas ubicadas en los llamados países de industrialización tardía, aprovecharon las tecnologías por medio de su absorción y aprendizaje. 


\section{Determinantes macroeconómicos de la IED en México (1970-2005)}

El segundo capítulo presenta las formas en que el gobierno mexicano se insertó en la globalización, mediante la modificación de distintas variables de teoría y política económica. Primero se analiza el ingreso de México al GATT en 1985, el cual, según los autores, "implicó cimentar nuevas bases para la inserción de IED a nuestro país en un contexto mundial y nacional esencialmente distinto" (p. 45). Posteriormente, con la firma del TLCAN, se consolidó una estrategia de crecimiento vía exportaciones, apoyada en flujos crecientes de IED. En su momento México consideró que la IED sería un proceso de competencia comercial, una palanca exportadora, sin embargo no fue así. La IED detuvo su dinamismo debido a varios factores, entre otros, crisis financiera; pugnas políticas e inseguridad social. Temas desarrollados a lo largo del segundo capítulo.

La gráfica 2.1 (p. 47), muestra datos interesantes del caso mexicano. Primero divide el periodo de 1970-2005 en cuatro subperiodos. El primero, de 1970 a 1981, se caracteriza por un alto ritmo de crecimiento del PIB, sin embargo, los flujos de IED no fueron representativos, lo cual para los autores pudo ser resultado de la escasa apertura económica y los altos costos laborales. El segundo subperiodo, 1981-1993, muestra la transición de la estrategia económica, caracterizada por bajo crecimiento económico e inestabilidad macroeconómica y social. Además, a lo largo de estos años, los autores destacan el ingreso de México al GATT, la rápida apertura comercial y la acelerada reducción de los costos laborales (caída de salarios reales, acompañado de la elevación de la productividad media). En el tercer subperiodo, 1993-1999, México muestra una fuerte integración con Norteamérica, lo cual permitió incrementar la participación del capital extranjero en sectores específicos relacionados con la modernización tecnológica, la exportación y los servicios de alta productividad. El último subperiodo, 1999-2005, se caracteriza por la recuperación del crecimiento y la venta de bancos.

Para los autores, la IED genera beneficios y costos. Entre los primeros tenemos: aumento en la producción, en el empleo, en los salarios y en las exportaciones. Entre los costos se destacan: deterioro en los términos de intercambio, descenso del ahorro y la inversión interna, desequilibrio del sector externo y tasa de desempleo. Pareciera que existe contradicción en el tema del empleo, porque por un lado los autores lo presentan como que éste se incrementa, y por otra parte como que disminuye, sin embargo aclaran: "La inercia demográfica y el lento crecimiento observado desde 1982 han hecho que la tasa de desempleo se mantenga en niveles elevados. Ante ello, se deduce que si bien la IED contribuye a generar empleos directos en los sectores en que participa $-y$ también indirectos en los sectores 
encadenados a ellos-, no es suficiente para disminuir sensiblemente la tasa de desempleo (p. 59).

Finalmente, se presentan algunas conclusiones preliminares e interesantes propuestas de política: "Debido a la apertura comercial, el PIB y el riesgo país resultaron exógenos a la IED, es posible afirmar que estas variables pueden ser consideradas como instrumentos poderosos de política económica” (p. 65).

La IED exógena al PIB busca sobre todo mercados dinámicos y no necesariamente mano de obra barata, ello posibilita la generación de economías de escala y de complementación, lo cual facilita los efectos de spillover de la IED sobre las economías receptoras y viceversa. El apoyo al crecimiento de la IED debe considerar: aplicar eficientemente reformas estructurales, políticas facilitadoras de la integración a la globalización, y aplicar la ley y la estabilidad política.

\section{Normatividad e IED por sectores, origen y destino}

El tercer capítulo presenta antecedentes de la IED en México (aspectos conceptuales y trabajos previos), normatividad, desempeño de la IED a nivel agregado, tendencias de la IED por origen y destino y, al igual que los anteriores capítulos, conclusiones y propuestas de política.

Los autores consideran tres temas importantes en el debate actual sobre IED: los encadenamientos mercantiles globales y su segmento, la competitividad sistémica y la eficiencia colectiva y la endogeneidad territorial, todos ellos desarrollados en el texto.

En el subtema denominado "Los antecedentes sobre la relevancia de la IED para la economía mexicana", se considera el trabajo de Romo Murillo (2001), quien llega a la siguiente conclusión para el caso de las fibras químicas y la farmacéutica: "por un lado [la IED] ha generado un sector moderno y con altos niveles de productividad, pero por otro lado ha desplazado a empresas mexicanas y no se ha probado la capacidad del sector local de poder absorber esta nuevas tecnologías" (p. 78.) Para los autores, la estabilidad macroeconómica y la apertura comercial no son condición suficiente para permitir un proceso de crecimiento sustentable en el largo plazo.

El análisis sobre la normatividad de la IED refleja que en materia de legislación, México desde inicios de la década de los noventa se ha rezagado. La Ley de Inversión Extranjera, que data de 1993, no ha tenido cambios importantes, por ello, se observa -dicen los autores- un claro estancamiento para atraer IED, la cual debiera tener como características principales la generación de procesos y segmentos de cadenas de valor. 
Por lo anterior proponen, "es indispensable actualizar, profundizar y ampliar el marco normativo para atraer inversión extranjera directa a México y con el objetivo de permitir un mayor grado de integración territorial (p. 141).

Los autores sugieren crear una ley de inversión extranjera ágil y transparente, que permita vincular la IED con el resto del aparato productivo, mediante programas de ciencia y tecnología.

Para aprovechar las ventajas que genera la IED orientada al sector servicios, se deben dar estímulos e incentivos a este sector. Los autores ejemplifican el desarrollo de la industria del software a través del programa Prosoft.

\section{Análisis de la ied por clases económicas y por entidad federativa}

En el cuarto capítulo, los autores presentan algunos antecedentes de la IED, argumentan que:

El intenso proceso de globalización de las economías nacionales durante las tres últimas décadas ha venido acompañado de un aumento sustancial de los flujos de IED. Ello refleja tanto la importancia de esta variable como su fuerte dinamismo, registrando tasas de crecimiento anual de 15 por ciento en los últimos 20 ańos. [...] Es inevitable reconocer que este fenómeno ha contribuido a la creación de nuevos mercados, tanto en los países desarrollados como en vías de desarrollo, ha intensificado los procesos de integración comercial y financiera de las economías, ha reconfigurado la composición geográfica de las empresas transnacionales y obligado a los gobiernos ha implementar diversas estrategias, en términos de políticas públicas, a fin de obtener mayor monto y beneficio de las inversiones en el exterior (p. 179).

Aunque los países desarrollan diferentes estrategias cuyo objetivo es la atracción de IED, las decisiones de una empresa para invertir se basan principalmente en la búsqueda de maximización de ganancias, la cual se encuentra sujeta a restricciones presupuestales, tecnológicas y de mercado.

Para los autores, los factores considerados por las empresas para invertir fuera de su región son:

a) El tamaño y dinamismo del mercado del país receptor.

b) El tamaño y dinamismo de la economía de origen que representa un proxy de la capacidad de sus empresas para invertir y diversificarse internacionalmente.

c) Los niveles de integración económica y apertura al exterior del país receptor y su participación en uniones comerciales aduaneras.

d) Los costos de producción y distribución como una forma de ganar ventajas competitivas. 
e) Las ventajas tecnológicas en referencia al país receptor y en el contexto internacional.

f) El contexto macroeconómico representado por una economía estable y en crecimiento, con escaso riesgo de inestabilidad y donde el marco general o regulatorio imponga certidumbre a largo plazo.

g) Particularidades regionales como cultura, idioma o marco institucional.

En este capítulo se presenta un modelo de cointegración con datos panel. Los autores identificaron a nivel de clases económicas un conjunto de variables que influyen en los flujos de la IED. Las variables se asocian al tamaño de mercado el cual se mide por la proporción de ventas estatales respecto al valor bruto de la producción, los costos laborales, las exportaciones, los costos no industriales, los costos de materias primas nacionales, y el gasto en investigación y desarrollo tecnológico.

Los resultados que se obtienen del modelo econométrico señalan que las empresas trasnacionales buscan aprovechar las ventajas que les ofrecen los países receptores. Existe un resultado interesante en este modelo. Los costos de las materias primas nacionales reportan una elasticidad negativa respecto de la IED. Es decir, es bastante limitada la capacidad de la industria nacional para incorporarse como abastecedor de insumos. Sus elevados costos influyen negativamente en la localización de la IED.

Para el caso específico de México, los autores observan que el destino de la IED en los estados es heterogéneo. Lo anterior es resultado de factores como costos laborales y grados de desarrollo o productividad heterogéneos.

Finalmente, el capítulo presenta las siguientes conclusiones: los países en desarrollo buscan activamente atraer la IED con el objeto de acelerar su desarrollo económico; y "Los costos laborales aproximados como el pago de remuneraciones respecto al valor bruto de la producción influyen de manera negativa en la IED, mostrando evidencia a favor de la hipótesis de que las empresas extranjeras consideran los costos laborales en sus decisiones de inversión" (p. 206).

Se presentan algunas propuestas entre las que destacan:

a) Diseñar una estrategia que permita que la IED contribuya a equilibrar el nivel de desarrollo por estados.

b) La decisión de invertir en México incluye también la localización geográfica específica. En este sentido, se propone que la IED contribuya a un desarrollo regional más equilibrado.

c) Invertir en tecnología, investigación y educación para incentivar a la IED. 
d) Desarrollar una política más activa y comprensiva no sólo para inducir a la IED, sino considerar sus características y localización.

\section{El origen de la IED. El caso de Japón}

El capítulo quinto tiene como objetivo mostrar la importancia de los flujos de la IED japonesa en México, y destacar sus características por sector, subsector, clase económica y destino.

La inversión japonesa al exterior tuvo su periodo de expansión a mediados de la década de los sesenta y principios de los setenta, lo cual fue resultado del continuo crecimiento del superávit comercial, por ello el gobierno de Japón incentivó la inversión al exterior. Durante los ochenta, este país se convirtió en uno de los principales exportadores de inversión extranjera. Las razones, los autores del texto la explican a partir de Ureta (1998) y Fung et al. (2002). La rápida apreciación del yen a partir de la segunda mitad de los ochenta y la burbuja económica de finales de esa misma década, generaron el efecto liquidez.

En lo referente al tema de México, se destaca que la IED de origen japonés tuvo características cíclicas durante el periodo 1994-2005. Algunas de sus particularidades es que ésta representó el quinto lugar en la economía mexicana. Destaca su participación en la industria manufacturera, particularmente en productos metálicos, maquinaria y equipo, así como otras industrias. En lo referente a ramas, durante el periodo de referencia, destaca la inversión en el sector automotriz con $77 \%$. Finalmente, la IED japonesa tiene sus mayores montos de inversión en el Distrito Federal, Baja California, Aguascalientes y Nuevo León.

Es importante señalar que este capítulo tiene una variada y extensa gama estadística acerca de la IED japonesa en México, entre la que destaca: distribución regional de los flujos, índice de especialización, principales empresas, IED realizada por concepto y en las principales cinco entidades federativas por cinco sectores de actividad económica, entre otras.

Entre las propuestas presentadas en el capítulo, destaca la necesidad de México para mejorar en el corto plazo las estadísticas de la IED japonesas. "Considerando el alto grado de concentración de la IED japonesa en México -por empresa, sectores, subsectores y clases económicas-, es conveniente llevar a cabo una encuesta periódica de este grupo de empresas para conocer y adelantarse a posibles eventos y problemáticas de la IED japonesa en el corto, mediano y largo plazos (pp. 251-252). 


\section{La IED según su destino. El caso de las empresas en Jalisco}

El capítulo sexto parte de la consideración que actualmente no existen investigaciones detalladas sobre la IED en Jalisco, ni sobre sus efectos territoriales.

Los autores matizan que "Si bien existe una serie de investigaciones sobre la industria maquiladora de exportación y particularmente sobre la industria electrónica, es relevante destacar esta significativa limitación sobre la falta de investigación sobre la temática regional. No obstante lo anterior, es relevante señalar al respecto que el gobierno del estado de Jalisco ha sido una de las entidades federativas más avanzadas en la promoción de la IED desde mediados de la década de los noventa" (pp. 265-266).

Para los autores, la riqueza de este capítulo estriba en su análisis detallado, del cual surgen una serie de conclusiones y propuestas, entre las que destacan:

- Revisar en los ámbitos federal y estatal los incentivos otorgados a la IED.

- El gobierno del estado de Jalisco debe adelantarse a los cambios futuros de la industria electrónica, con el objeto de enfrentar la competencia de China que busca atraer IED de otras latitudes.

- Se debe mejorar la base proveedora local, para lograrlo los autores proponen organizar seminarios y diplomados para conocer las nuevas estrategias de los competidores mundiales, y especificar nuevos requerimientos para los proveedores locales.

En el apartado de las conclusiones, los autores señalan:

el presente documento, dividido en siete capítulos y un anexo, ha analizado el tema de los determinantes, condiciones y efectos de la IED en México con detalle desde múltiples perspectivas: los debates y el "estado del arte" conceptual, las condiciones internacionales, una perspectiva macroeconómica, los determinantes, las condiciones y los efectos de la IED para la manufactura, sectores, ramas y clases económicas, el tema del registro de la IED y sus estadísticas, su normatividad, así como tres capítulos dedicados al origen y destino de la IED en México, cada capítulo cuenta con sus respectivas conclusiones y propuestas; las 46 propuestas de política responden a los temas concretos de los respectivos capítulos (p. 305).

Recibida: 25 de febrero de 2009. Aceptada: 15 de octubre de 2009. 
Maximiliano Gracia-Hernández. Es doctor en economía internacional y desarrollo económico por la Facultad de Económicas y Empresariales de la Universität de Barcelona; asimismo realizó sus estudios de maestría en la Universidad Internacional de Andalucía, y la licenciatura en la Facultad de Economía de la Universidad Nacional Autónoma de México (UNAM). Actualmente es investigador candidato en el Sistema Nacional de Investigadores (SNI) y profesor-investigador de tiempo completo titular A en la Universidad del Mar, donde se encuentra adscrito al Instituto de Estudios Internacionales. Sus líneas de investigación actuales son: la Unión Europea, desarrollo económico, industria textil y confección. Entre sus publicaciones destacan: "Consideraciones generales en torno a la política económica”, Revista Ciencia y Mar, 34, Puerto Ángel, Oaxaca, pp. 25-32 (2009); "Efectos económicos de los criterios de convergencia en el proceso de inserción de Bulgaria y Rumania a la Unión Europea", Economía, Sociedad y Territorio, El Colegio Mexiquense, Ix (30), Toluca, pp. 229-258 (2009); "La industria del calzado en León, Guanajuato México. Análisis a partir de las economías externas y de urbanización", Economía Autónoma, 3, Universidad Autónoma Latinoamericana, Medellín, Colombia, pp. 15-32 (2009). 